\title{
Feasibility and safety of continuous retrograde administration of Del Nido cardioplegia: a case series
}

Marc Najjar ${ }^{\dagger}$, Isaac George ${ }^{*}{ }^{\dagger}$, Hirokazu Akashi, Takashi Nishimura, Halit Yerebakan, Linda Mongero, James Beck, Stephen C. Hill, Hiroo Takayama and Mathew R. Williams

\begin{abstract}
Background: Del Nido (DN) cardioplegia, a calcium-free, hyperkalemic solution containing lidocaine and magnesium has been developed to help reduce intracellular calcium influx and the resulting myocyte damage in the immediate postischemic period following cardiac arrest. DN cardioplegia has been used for pediatric cardiac surgery but its use in complex reoperative surgery has not been studied. We specifically report the outcomes of patients undergoing reoperative cardiac surgery after previous coronary artery bypass grafting with a patent internal mammary artery (IMA).
\end{abstract}

Methods: Patients undergoing reoperative cardiac surgery with prior coronary bypass grafting surgery were studied between 2010 and 2013. Fourteen patients were identified who required continued retrograde cardioplegia administration. In all cases, an initial antegrade dose was given, followed by continuous retrograde administration. Demographics, co-morbidities, intra-operative variables including cardioplegia volumes, post-operative complications, and patient outcomes were collected.

Results: The mean age of all patients was $73.3+/-6.7$ years, and $93 \%$ were male. Aortic cross clamp time and cardiopulmonary bypass times were $81+/-35$ and $151+/-79$ mins, respectively. Antegrade, retrograde and total cardioplegia doses were $1101+/-398,3096+/-3185$ and $4367+/-3751 \mathrm{ml}$, respectively. An average of 0.93+/-0.92 inotropes and $1.50+/-0.76$ pressors were used on ICU admission after surgery. ICU and total hospital lengths of stay were $5.5+/-7.4$ and $9.6+/-8.0$ days, respectively. Complications occurred in two patients (14\%) (pneumonia and prolonged mechanical ventilation) and new arrhythmias occurred in five patients (36\%) (four new-onset atrial fibrillation and one pulseless electrical activity requiring 2 min of chest compression). No perioperative myocardial infarctions were noted based on electrocardiograms and cardiac serum markers. Postoperatively, left ventricular function was preserved in all patients whereas two patients (14\%) had mild decrease in right ventricular function as assessed by echocardiography. No mortality was observed.

Conclusion: Del Nido cardioplegia solution provides acceptable myocardial protection for cardiac surgery that requires continuous retrograde cardioplegia administration. DN cardioplegia's administration in a continuous retrograde fashion with a patent IMA is believed to provide adequate myocardial protection while avoiding injuring the IMA through dissection and clamping.

Keywords: Myocardial protection, Cardioplegia, Reoperation, Outcomes, Patient safety

\footnotetext{
* Correspondence: ig2006@cumc.columbia.edu

'Equal contributors

Department of Surgery, Division of Cardiothoracic Surgery, College of Physicians and Surgeons of Columbia University, New York Presbyterian Hospital, MHB 7GN-435, 177 Fort Washington Ave, New York 10032, NY, USA
} 


\section{Background}

Retrograde cardioplegia via the coronary sinus has become an essential method to deliver cardioplegia to the left ventricle, particularly in the setting of critical coronary stenosis, aortic insufficiency, or other factors precluding antegrade cardioplegia administration [1]. Patent bypass grafts after coronary artery bypass grafting (CABG), such as an internal mammary artery (IMA) graft, can prevent full cardioplegic arrest if unable to be isolated and clamped; in this situation, continuous retrograde cardioplegia has been administered using whole blood cardioplegia with reduced potassium concentration to achieve ventricular fibrillatory arrest. The most popular technique to deal with a patent IMA is to clamp both the aorta and the patent graft and administer antegrade and retrograde cardioplegia [2]. However, if an area of the myocardium is very dependent on the patent IMA, clamping the graft may cause inadequate myocardial protection. Moreover, the dissection and clamping of the IMA have been linked with the associated morbidity and mortality of the procedure as they could cause inadvertent injury to the graft [3]. Other groups have reported satisfactory results with selective use of continuous retrograde cardioplegia administration in patients whose IMA was deemed technically challenging to safely dissect and clamp [2, 4].

Del Nido cardioplegia (DN) (Compass- Baxter Healthcare Inc., Edison, NJ) has been in use for over 20 years in the pediatric populations. It is delivered cold $\left(4{ }^{\circ} \mathrm{C}\right)$ at a ratio of one part blood to four parts crystalloid, and achieves arrest using a low calcium, hyperkalemic solution with lidocaine and magnesium additive for a total volume of 1 L [5-8]. After mixture of the blood and crystalloid components, the final concentrations of $\mathrm{Na}^{+}, \mathrm{K}^{+}$and $\mathrm{Ca}^{2+}$ in the $\mathrm{DN}$ solution are respectively: 38,22 and $0.24 \mathrm{mmol} / \mathrm{L}$. The safety of its use in adult cardiac surgery has been recently reported in three series from our institution evaluating specific situations of cardiac surgeries [9-11]. These studies showed that DN cardioplegia could be safely used in patients undergoing CABG for acute myocardial infarction (AMI), aortic valve replacement (AVR) or isolated reoperative AVR. They all showed that morbidity and mortality in patients receiving $\mathrm{DN}$ cardioplegia is comparable to those of patients receiving standard whole blodd (WB) cardioplegia. We report our use of $\mathrm{DN}$ cardioplegia given as a continuous retrograde infusion in the setting of complex, reoperative cardiac surgeries with a patent prior IMA unable to be isolated. DN solution given in a continuous retrograde fashion is, unlike the original solution, made of four units of blood to one unit of crystalloid in order to reduce hemodilution.

\section{Methods}

All patients who underwent reoperative cardiac surgeries after prior CABG between 2010 and 2013 were reviewed retrospectively, and a total of 14 patients were identified who received continuous retrograde DN. In all cases, a patent IMA was present and was not clamped during cross-clamp. Patient characteristics were collected, including age, gender, body surface area, pre-operative comorbidities and surgical risk factors [hyperlipidemia, prior myocardial infarct (MI), hypertension, stroke, chronic obstructive pulmonary disease, chronic kidney disease with baseline creatinine $>2.0 \mathrm{mg} / \mathrm{dL}$, atrial fibrillation, congestive heart failure by New York Heart Association functional classification, prior CABG], left ventricular ejection fraction (LVEF), number of inotropes and vasopressors on intensive care unit (ICU) admission, days on ventilator, length of postoperative ICU stay (ICULOS), total post-operative hospital length of stay (THLOS), in-hospital mortality, and post-operative complications [transfusion, sepsis or endocarditis, sternal wound infection, gastrointestinal bleeding, MI, reoperation for bleeding, acute renal injury, stroke, transient ischemic attach, need for permanent pacemaker, prolonged mechanical ventilation and need for reintubation]. This study met all guidelines of the Institutional Review Board of Columbia University Medical Center.

Using mild systemic hypothermia $\left(32-34^{\circ} \mathrm{C}\right)$, antegrade cardioplegia was first administered after cross clamp (XC) (500-1000 cc), followed by 500-750 сc retrograde. DN cardioplegia was the only cardioplegia solution used and was delivered at a temperature of $4^{\circ}$ C. For the initial antegrade and retrograde doses, the solution was administered as a 1:4 blood to crystalloid ratio with concentrations of $\mathrm{Na}^{+}, \mathrm{K}^{+}, \mathrm{Ca}^{2+} \mathrm{Mg}^{2+}$ and lidocaine of respectively: 38, 22, 0.24, 6.6 and $104 \mathrm{mg} / \mathrm{L}$. Once ventricular fibrillation was achieved (typically at approximately $1 \mathrm{~L}$ ), cardioplegia was switched to continuous retrograde using a 4:1 blood to crystalloid ratio to prevent hemodilution, the modified solution has concentrations of $\mathrm{Na}^{+}, \mathrm{K}^{+}, \mathrm{Ca}^{2+}, \mathrm{Mg}^{2+}$ and lidocaine of respectively: 115, 9.2, 1, 2.4 and $26 \mathrm{mg} / \mathrm{L}$ (Tables 1 and 2).

Table 1 Composition of del Nido Cardioplegia (before mixing with blood)

\begin{tabular}{|c|c|c|}
\hline & $\begin{array}{l}\text { Whole Blood } \\
\text { Cardioplegia }\end{array}$ & $\begin{array}{l}\text { del Nido } \\
\text { Cardioplegia }\end{array}$ \\
\hline Carrier (1 L) & D5W & Plasma-lyte A \\
\hline Blood: Crystalloid ratio & $4: 1$ & $1: 4$ \\
\hline $\mathrm{KCl}(\mathrm{mEq})$ & 80 & 26 \\
\hline $\mathrm{NaHCO}_{3}(\mathrm{mEq})$ & 30 & 13 \\
\hline Mannitol (g) & 12.5 & 3.3 \\
\hline Lidocaine (mg) & 0 & 130 \\
\hline Magnesium (g) & 0 & 2 \\
\hline
\end{tabular}


Table 2 Final concentrations in del Nido Cardioplegia solutions (after mixing with blood)

\begin{tabular}{lll}
\hline Carrier & $\begin{array}{l}\text { Initial single dose antegrade } \\
\text { and retrograde } \\
\text { Plasma-lyte A }\end{array}$ & $\begin{array}{l}\text { Continuous } \\
\text { retrograde } \\
\text { Plasma-lyte A }\end{array}$ \\
\hline Blood: Crystalloid ratio & $1: 4$ & $4: 1$ \\
$\mathrm{~K}^{+}(\mathrm{mmol} / \mathrm{L})$ & 22 & 9.2 \\
$\mathrm{Na}^{+}(\mathrm{mmol} / \mathrm{L})$ & 38 & 115 \\
$\mathrm{Ca}^{2+}(\mathrm{mmol} / \mathrm{L})$ & 0.24 & 1.0 \\
$\mathrm{Lidocaine}(\mathrm{mg} / \mathrm{L})_{\mathrm{Mg}^{2+}(\mathrm{mmol} / \mathrm{L})}^{104}$ & 6.6 & 26 \\
\hline
\end{tabular}

Retrograde flow was maintained at approximately $40 \mathrm{ml} /$ $\mathrm{kg} / \mathrm{min}$ for a coronary sinus pressure of $20-30 \mathrm{mmHg}$. Particular attention was made to continuously check the coronary sinus balloon pressure and maintain it at 20$30 \mathrm{mmHg}$ and to frequently watch the left main coronary ostia to check for blood return. No redosing was required. However, if significant electrical activity was encountered, a full 1:4 dose cardioplegia dose would have been given retrograde or via the coronary ostia.

Cardioplegia was intermittently interrupted for less than $5 \mathrm{~min}$ for the purposes of visualization, especially during valve debridement and when placing annular sutures in the left coronary sinus. The operative details that were collected included cardiopulmonary bypass (CPB) and $\mathrm{XC}$ time, ischemic time, doses of antegrade and retrograde cardioplegia, lowest body temperature and number of transfusions.

\section{Results}

\section{Patient demographics}

The baseline pre-operative patients' characteristics are summarized in Table 3. Mean age was $73.3 \pm 6.7$ years (range 61-83 years). Thirteen patients (93\%) were males, and most of them (86 \%) had hypertension and dyslipidemia. Mean LVEF was $44 \pm 16 \%$. The types of reoperative surgeries were as follows: nine isolated Aortic Valve Replacement (AVR), 1 isolated Mitral Valve Replacement (MVR), 1 AVR/MVR/Tricuspid Valve Repair (TVr), 1 CABG/AVR/Mitral Valve repair (MVr), 1 MVR/TVr, and 1 Aortic dissection repair. Mean Society of Thoracic Surgeon predicted risk of mortality score was $4.3 \pm 2.1$.

\section{Intra-operative variables}

Total $\mathrm{CPB}$ and $\mathrm{XC}$ times were within an acceptable range, $151 \pm 79$ and $81 \pm 35$ min respectively, and no intraoperative complications related to cardioplegia administration were noted. Antegrade, retrograde and total cardioplegia doses were $1101 \pm 398,3096 \pm 3185$ and $4367 \pm 3751 \mathrm{ml}$, respectively. Ventricular fibrillation was achieved in all patients. Mechanical circulatory support
Table 3 Baseline Demographics

\begin{tabular}{ll}
\hline Number & 14 \\
\hline Age, year (mean \pm SD) & $73.3 \pm 6.7$ \\
Male, $\mathrm{n}(\%)$ & $13(93)$ \\
$\mathrm{BMI}, \mathrm{kg} / \mathrm{m}^{2}$ (mean $\left.\pm \mathrm{SD}\right)$ & $27 \pm 4.0$ \\
$\mathrm{BSA} \mathrm{m} \mathrm{m}^{2}$ (mean $\left.\pm \mathrm{SD}\right)$ & $1.97 \pm 0.16$ \\
Diabetes, $\mathrm{n}(\%)$ & $5(36)$ \\
Hypertension, $\mathrm{n}(\%)$ & $12(86)$ \\
Dyslipidemia (\%) & $12(86)$ \\
COPD, $\mathrm{n}(\%)$ & $2(14)$ \\
PVD, $\mathrm{n}(\%)$ & $4(29)$ \\
Stroke, $\mathrm{n}(\%)$ & $2(14)$ \\
Atrial fibrillation, $\mathrm{n}(\%)$ & $5(36)$ \\
Creatinine, $>2(\mathrm{mg} / \mathrm{dL}) \mathrm{n}(\%)$ & $2(14)$ \\
LVEF, \% (mean $\pm \mathrm{SD})$ & $44 \pm 16$ \\
NYHA grade (mean $\pm \mathrm{SD})$ & $2.1 \pm 1.1$ \\
STS score (mean $\pm \mathrm{SD})$ & $4.3 \pm 2.1$ \\
\hline
\end{tabular}

Definitions: $B M I$ body mass index, $B S A$ body surface area, COPD chronic obstructive pulmonary disease, $P V D$ peripheral vascular disease, LVEF left ventricular ejection fraction, NYHA New York Heart Association, STS society of thoracic surgery

was not required in any patient whereas an intra-aortic balloon pump was placed in only one patient. The intraoperative measurements are summarized in Table 4 .

\section{Postoperative outcomes}

Postoperative complications occurred in two patients (14\%), both had pneumonia complicated by sepsis and a prolonged mechanical ventilation time (8 and 24 days). Five patients (36 \%) had new arrhythmias postoperatively (four had new-onset atrial fibrillation and one had pulseless electrical activity requiring 2 min of chest compression). ICULOS and THLOS were respectively $5.5 \pm$ 7.4 and $9.6 \pm 8.0$ days. On average, patients needed 0.93 \pm 0.92 inotropes and $1.50 \pm 0.76$ vasopressors on ICU admission. No perioperative MIs (PMI) [12] were diagnosed. Biomarkers were ordered whenever symptoms and/or EKG signs of possible PMI were suspected, as well as when patients were enrolled in clinical trials mandating serial cardiac markers level assessment.

Table 4 Intraoperative measurements

\begin{tabular}{ll}
\hline Cross-clamp time $($ min, mean $\pm S D)$ & $81 \pm 35$ \\
CPB time $(m i n$, mean $\pm S D)$ & $151 \pm 79$ \\
ACP dose $(\mathrm{mL}$, mean $\pm S D)$ & $1101 \pm 398$ \\
RCP dose $(\mathrm{mL}$, mean $\pm S D)$ & $3096 \pm 3185$ \\
TCP dose $(\mathrm{mL}$, mean $\pm S D)$ & $4367 \pm 3751$ \\
Lowest temperature $\left({ }^{\circ} \mathrm{C}\right.$, mean $\left.\pm \mathrm{SD}\right)$ & $32.36 \pm 3.67$
\end{tabular}

Definitions: $C P B$ cardiopulmonary bypass, $A C P$ antegrade cardioplegia, $R C P$ retrograde cardioplegia, $T C P$ total cardioplegia 
Troponin I and CKMB were ordered for four patients (29\%), of which actually only one had a suspicion of PMI, the other three were part of clinical trials. Average postoperative Troponin I was $1.01 \pm 0.335 \mathrm{ng} / \mathrm{mL}$ (reference range $0.00-0.008 \mathrm{ng} / \mathrm{mL}$ ) and CKMB $3.58 \pm$ $3.47 \mathrm{ng} / \mathrm{mL}$ (reference range $0.5-5.5 \mathrm{ng} / \mathrm{mL}$ ). Immediate preoperative and postoperative trans-esophageal echocardiographs (TEE) as well as predischarge transthoracic echocardiographs were reviewed in all patients to assess ventricular function preservation. All patients had preservation of left ventricular (LV) function and only three patients $(21 \%)$ had slightly worsened right ventricular (RV) function immediately postop (no dysfunction preop to mild dysfunction postop), which in 1 case (7\%) recovered completely by the time the patient was discharged. Moreover, two patients (14\%) had an improvement in RV function from preop to postop with a mild dysfunction not appreciated on the postop TEE. All patients were discharged from the hospital alive for a $0 \% 30$-day and inhospital mortality. Follow-up duration was $361 \pm 356$ days and midterm results were excellent with a $100 \%$ survival rate. Moreover, on follow-up echocardiography, there was preservation of LV function in all 14 patients and no new RV dysfunction. Postoperative variables are summarized in Table 5.

\section{Discussion}

The patent IMA graft poses a special concern for surgeons - its dissection and isolation can pose risk, and injury to this vessel during surgery is associated with extremely high rates of mortality [13]. Thus, continuous retrograde administration of cardioplegia in the midst of a patent IMA has become an accepted technique for effective myocardial preservation [14]. Other strategies to manage myocardial protection during reoperative cardiac surgeries with a patient IMA have been described. The

\begin{tabular}{ll} 
Table 5 Postoperative variables & \\
\hline Inotropes on ICU admission, number (mean \pm SD) & $0.93 \pm 0.92$ \\
Pressors on ICU admission, number (mean \pm SD) & $1.50 \pm 0.76$ \\
Ventilation, days (mean \pm SD) & $3.6 \pm 6.5$ \\
PRBCs, units (mean \pm SD) & $2.86 \pm 4.96$ \\
Post-op EF, \% (mean \pm SD) & $45 \pm 14$ \\
ICULOS, days (mean \pm SD) & $5.5 \pm 7.4$ \\
THLOS, days (mean \pm SD) & $9.6 \pm 8.0$ \\
Complications, $n(\%)$ & $2(14)$ \\
New arrhythmia, $n(\%)$ & $5(36)$ \\
30-days Mortality, $\mathrm{n}(\%)$ & $0(0)$ \\
Follow-up duration, days (mean \pm SD) & $361 \pm 356$ \\
Cumulative mortality, $\mathrm{n}(\%)$ & $0(0)$ \\
\hline
\end{tabular}

Definitions: PRBCS packed red blood cells, EF ejection fraction, ICULOS intensive care unit length of stay, THLOS total hospital length of stay most popular technique is clamping both the aorta and the patent IMA graft with antegrade and retrograde infusion of cardioplegia. The main limitation of that technique are the fact that some areas of the myocardium might be dependent on the patent graft and simply clamping it may lead to suboptimal myocardial protection, as well as the risk of injury to the graft that comes with dissection and clamping [2,3]. Other strategies that have been described but have not gained widespread popularity are: deep hypothermia alone [15], continuously perfused beating heart [16], endovascular occlusion or supraclavicular clamping of the patent IMA $[17,18]$. Despite providing adequate control of blood flow through the graft, manipulation of the graft by itself can cause injury and should probably be avoided whenever possible. Here we report our experience with the combination of antegrade, retrograde and continuous retrograde hypothermic cardioplegia through a patent IMA using Del Nido cardioplegia, a single dose hyperkalemic agent. Our data suggests that we achieved effective myocardial preservation using continuous retrograde administration, as evidenced by the absence of perioperative myocardial infarction, a good LV and RV function preservation, reasonable $\mathrm{CPB}$ and $\mathrm{XC}$ times, low amount of vasoactive medications post-bypass, and the lack of need for additional mechanical circulatory assistance. Thus, the strategy of antegrade, retrograde, and continuous retrograde cardioplegia administration provided sufficient protection for surgery to be completed without significant hindrance. Spontaneous recovery of rhythm occurred in all patients, and there was only one case of low cardiac output syndrome which required the intraoperative insertion of an IABP. Part of these positive outcomes may be attributed to the fact that the anterior wall of the LV is continuously perfused via the IMA. Nonetheless, use of DN cardioplegia does offer some distinct advantages, such as uninterrupted conduct of surgery, stabilization of calcium handling regulation during the ischemic period [19], less need for systemic cooling and a lower total volume of cardioplegia.

Although not fully understood yet, ischemia-reperfusion injury is thought to be at least partly due to an increase in intracellular calcium concentrations in postischemic myocytes. This increase in $\mathrm{Ca}^{2+}$ is related to an increase in intracellular $\mathrm{Na}^{+}$during the ischemic period, causing the $\mathrm{Na}^{+} / \mathrm{Ca}^{2+}$ channel to increase calcium influx [20-22] . As a result of high levels of intracellular $\mathrm{Ca}^{2+}$, the myocytes hypercontract causing irreversible damage to the cytoskeleton and even cell death [20] . Therefore, Del Nido cardioplegia provides a theoretical advantage over other cardioplegia solutions in that it is calcium-free and contains lidocaine, an $\mathrm{Na}^{+}$channel blocker, as well as magnesium, a calcium competitor. All of these components contribute to limiting calcium influx in the postperfusion phase. The effectiveness of these mechanisms has been 
demonstrated in both animal and pediatric hearts, while $\mathrm{DN}$-arrested rats hearts had a significantly lower intracellular calcium levels when compared to hearts arrested with regular whole blood (WB) cardioplegia [23], pediatric patients receiving DN solution had in turn a reduction in troponin $\mathrm{T}$ release following surgery compared to patients receiving the WB solution [19].

A lower total volume of cardioplegia allows a reduction of hemodilution while on bypass and consequently a decreased need for transfusion. The advantages of decreasing hemodilution have been demonstrated with WB or undiluted blood (microplegia) cardioplegia solutions, which offer a better myocardial protection [24] and limit myocardial edema [25] compared with crystalloid cardioplegia.

\section{Conclusion}

As a conclusion, del Nido cardioplegia solution can be used as a safe alternative to whole blood solutions in cardiac surgeries requiring the administration of continuous retrograde cardioplegia.

\section{Abbreviations}

DN: Del Nido cardioplegia; CABG: coronary artery bypass grafting; IMA: internal mammary artery; MI: myocardial infarct; LVEF: left ventricular ejection fraction; ICU: intensive care unit; ICULOS: intensive care unit length of stay; THLOS: total post-operative hospital length of stay; XC: cross lamp; CPB: cardiopulmonary bypass; MVR: Mitral Valve Replacement; AVR: aortic valve replacement; TVr: Tricuspid Valve Repair; PMI: perioperative Ml; TEE: trans-esophageal echocardiographs; LV: left ventricle; RV: right ventricle; WB: whole blood.

\section{Competing interests}

The authors declare that they have no competing interests.

\section{Authors' contributions}

Conceived the study: MN, IG, MRW. Data collection: LM, JB, SCH, HA, HY Data analysis: MN, IG, MRW. Manuscript writing: MN, IG, MRW. Statistical Analysis: MN. Editing: IG, MN, MRW. Critical Review: IG, TN, HT, MRW. All authors read and approved the final manuscript.

Received: 3 March 2015 Accepted: 18 November 2015

Published online: 26 November 2015

\section{References}

1. Bar-El Y, Kophit A, Cohen O, Kertzman V, Milo S. Minimal dissection and continuous retrograde cardioplegia for aortic valve replacement in patients with a patent left internal mammary artery bypass graft. J Heart Valve Dis. 2003;12(4):454-7.

2. Borger MA, Rao V, Weisel RD, Floh AA, Cohen G, Feindel CM, et al. Reoperative coronary bypass surgery: Effect of patent grafts and retrograde cardioplegia. J Thorac Cardiovasc Surg. 2001:121:83-90.

3. Gillinov AM, Casselman FP, Lytle BW, Blackstone EH, Parsons EM, Loop FD, et al. Injury to a patent left internal thoracic artery graft at coronary reoperation. Ann Thorac Surg. 1999;67:382-6.

4. Nakajima M, Tsuchiya K, Fukuda S, Morimoto H, Mitsumori Y, Kato K, et al. Aortic operation after previous coronary artery bypass grafting: management of patent grafts for myocardial protection. Jpn J Thorac Cardiovasc Surg. 2006;54:155-9

5. Matte GS, del Nido PJ. History and Use of del Nido Cardioplegia Solution at Boston Children's Hospital. J Extra Corpor Technol. 2012:44:98-103.

6. del Nido P, Wilson G, Mickle D. The role of cardioplegic solution buffering in myocardial protection. A biochemi- cal and histopathological assessment. J Thorac Cardiovasc Surg. 1985;89:689-99.

7. Rebeyka I, Axford-Gatley R, Bush B, del Nido PJ, Mickle DA, Romaschin AD, et al. Calcium paradox in an in vivo model of mutidose cardioplegia and moderate hypothermia. Prevention with diltiazem or trace calcium levels. J Thorac Cardiovasc Surg. 1990;99:475-83.

8. Ohkado A, Cao-Danh H, Sommers E, del Nido P. Evaluation of highly buffered low-calcium solution for long-term preservation of the heart. Comparison with University of Wisconsin solution. J Thorac Cardiovasc Surg. 1994;108:762-71.

9. Yerebakan H, Sorabella RA, Najjar M, Takayama H, Williams MR, Naka Y, et al. Del Nido Cardioplegia can be safely administered in high-risk coronary artery bypass grafting surgery after acute myocardial infarction: a propensity matched comparison. J Cardiothorac Surg. 2014;9:141. doi:10.1186/ s13019014-014-5.

10. Sorabella RA, Akashi H, Yerebakan H, Najjar M, Mannan A, Williams MR, et al. Myocardial protection using Del Nido cardioplegia solution in adult reoperative aortic valve surgery. J Card Surg. 2014;29(4):445-9. doi:10.1111/ jocs. 12360.

11. Takeyoshi Ota, Halit Yerebakan, Robert C Neely, Linda Mongero, Isaac George, Hiroo Takayama, et al. Short-term outcomes in adult cardiac surgery in the use of del Nido cardioplegia solution. Perfusion. 2015, doi: 10. $1177 / 0267659115599453$

12. Thygesen K, Alpert JS, White HD. for the Joint ESC/ACCF/AHAWHF Task Force for the Redefinition of Myocardial Infarction. Universal definition of myocardial infarction. J Am Coll Cardiol. 2007;50:2173-95.

13. Coltharp WH, Decker MD, Lea 4th JW, Petracek MR, Glassford Jr DM, Thomas $\mathrm{Jr}$ CS, et al. Internal mammary artery graft at reoperation: risks, benefits, and methods of preservation. Ann Thorac Surg. 1991;52(2):225-8.

14. Byrne JG, Karavas AN, Filsoufi F, Mihaljevic T, Aklog L, Adams DH, et al. Aortic valve surgery after previous coronary artery bypass grafting with functioning internal mammary artery grafts. Ann Thorac Surg. 2002;73(3): 779-84.

15. Ueda T, Kawata T, Sakaguchi H, Tabayashi N, Abe T, Hirose T, et al. Aortic valve replacement in a patient with a patent internal thoracic artery graft. Ann Thorac Surg. 2004;77:718-20.

16. Sutherland FW, West M, Pathi V. Aortic valve replacement with continuously perfused beating heart in patients with patent bypass conduits. Eur J Cardiothorac Surg. 2004;26:834-6.

17. Kuralay E, Cingöz F, Günay C, Oz BS, Küçükarslan N, Yildrim V, et al. Supraclavicular control of patent internal thoracic artery graft flow during aortic valve replacement. Ann Thorac Surg. 2003;75:1422-8.

18. Fuzellier JF, Metz D, Poncet A, Saade YA. Endovascular control of patent internal thoracic artery graft in aortic valve surgery. Ann Thorac Surg. 2005; 79:el7-8.

19. O'Brien J, Howlett S, Burton H, O'Blenes SB, Litz DS, Friesen CL. Pediatric cardioplegia strategy results in enhanced calcium metabolism and lower serum troponin t. Ann Thorac Surg. 2009;87:1517-23.

20. Piper HM, Garcia-Dorado D. Prime causes of rapid cardiomyocyte death during reperfusion. Ann Thorac Surg. 1999;68:1913-9.

21. van Emous JG, Nederhoff MG, Ruigrok TJ, van Echteld CJ. The role of the Na ${ }^{+}$channel in the accumulation of intracellular $\mathrm{Na}^{+}$during myocardial ischemia: Consequences for post- ischemic recovery. J Mol Cell Cardiol. 1997; 29:85-96.

22. Choi YH, Cowan DB, Wahlers TC, Hetzer R, del Nido PJ, Stamm C. Calcium sensitisation impairs diastolic relaxation in post-ischemic myocardium: Implications for the use of $\mathrm{Ca}^{2+}$ sensitising inotropes after cardiac surgery. Eur J Cardiothorac Surg. 2010;37:376-83.

23. O'Blenes SB, Friesen $\mathrm{CH}$, Ali A, Howlett $\mathrm{S}$. Protecting the aged heart during cardiac surgery: the potential benefits of del Nido cardioplegia. J Thorac Cardiovasc Surg. 2011;141:762-70. doi:10.1016/j.jtcvs.2010.06.004

24. McCann 2nd UG, Lutz CJ, Picone AL, Searles B, Gatto LA, Dilip KA, et al. Whole blood cardioplegia (minicardioplegia) reduces myocardial edema after ischemic injury and cardiopulmonary bypass. J Extra Corpor Technol. 2006;38:14-21

25. Guru V, Omura J, Alghamdi AA, Weisel R, Fremes SE. Is blood superior to crystalloid cardioplegia? A meta-analysis of randomized clinical trials. Circulation. 2006;1 14:1331-8. doi:10.1161/CIRCULATIONAHA.105.001644. 